\title{
Demography and Viability of a Hunted Population of Polar Bears
}

\author{
MITCHELL K. TAYLOR, ${ }^{1}$ JEFF LAAKE, ${ }^{2}$ PHILIP D. McLOUGHLIN,${ }^{3,4}$ ERIK.W. BORN, ${ }^{5}$ H. DEAN CLUFF, ${ }^{6}$ \\ STEVEN H. FERGUSON,,${ }^{3,7}$ AQQALU ROSING-ASVID, ${ }^{5}$ RAY SCHWEINSBURG ${ }^{6,8}$ and FRANÇOIS MESSIER ${ }^{3}$
}

(Received 26 July 2004; accepted in revised form 15 December 2004)

\begin{abstract}
We estimated demographic parameters and harvest risks for a population of polar bears (Ursus maritimus) inhabiting Baffin Bay, Canada and Greenland, from 1974 to 1997. Our demographic analysis included a detailed assessment of age- and sex-specific survival and recruitment from 1221 marked polar bears, which used information contained within the standing age distribution of captures and mark-recapture analysis performed with Program MARK. Unharvested (natural) survival rates for females $( \pm 1 \mathrm{SE}$ ) from mark-recapture analysis were $0.620 \pm 0.095$ (cubs), $0.938 \pm 0.042$ (ages 1-4), $0.953 \pm$ 0.020 (ages 5-20), and $0.919 \pm 0.046$ (ages 21+). Total (harvested) survival rates for females were reduced to $0.600 \pm 0.096$ (cubs), $0.901 \pm 0.045$ (ages 1-4), $0.940 \pm 0.021$ (ages 5-20), and $0.913 \pm 0.047$ (ages 21+). Mean litter size was $1.59 \pm 0.07$ cubs, with a mean reproductive interval of $2.5 \pm 0.01$ years. By age 5 , on average $0.88 \pm 0.40$ of females were producing litters. We estimated the geometric means ( \pm bootstrapped SDs) for population growth rates at stable age distribution as $1.055 \pm 0.011$ (unharvested) and $1.019 \pm 0.015$ (harvested). The model-averaged, mark-recapture estimate of mean abundance ( \pm 1 SE) for years 1994-97 was $2074 \pm 266$ bears, which included $1017 \pm 192$ females and $1057 \pm 124$ males. We incorporated demographic parameters and their error terms into a harvest risk analysis designed to consider demographic, process, and sampling uncertainty in generating likelihoods of persistence (i.e., a stochastic, harvest-explicit population viability analysis). Using our estimated harvest of polar bears in Baffin Bay ( 88 bears/yr), the probability that the population would decline no more than could be recovered in five years was 0.95 , suggesting that the current hunt is sustainable.
\end{abstract}

Key words: demography, harvest, mark-recapture, polar bear, Ursus maritimus, population viability analysis, program MARK, recruitment, survival

RÉSUMÉ. De 1974 à 1997, on a évalué les paramètres démographiques d'une population d'ours polaires (Ursus maritimus) habitant la baie de Baffin (Canada et Groenland), ainsi que les risques associés à leur prélèvement. Notre analyse démographique comprenait un bilan détaillé de la survie et du recrutement par âge et par sexe, bilan mené sur 1221 ours polaires étiquetés et qui faisait appel à l'information contenue dans les limites de la structure d'âge des captures à un moment précis, ainsi que des analyses de marquage-recapture réalisées avec le logiciel MARK. Les taux de survie sans prélèvements (c'est-à-dire naturels) des femelles ( \pm 1 erreur-type) tirés de l'analyse de marquage-recapture étaient les suivants: 0,620 $\pm 0,095$ (oursons), 0,938 $\pm 0,042$ ( $1-4$ ans), $0,953 \pm 0,020$ ( $5-20$ ans) et $0,919 \pm 0,046$ ( 21 ans et plus). Les taux de survie globaux (avec prélèvements) des femelles diminuaient à: 0,600 $\pm 0,096$ (oursons), 0,901 $\pm 0,045$ ( $1-4$ ans), 0,940 $\pm 0,021$ (5-20 ans) et 0,913 $\pm 0,047$ ( 21 ans et plus). La taille moyenne des portées était de 1,59 $\pm 0,07$ ourson avec des intervalles moyens de reproduction de 2,5 $\pm 0,01$ ans. Arrivées à l'âge de cinq ans, en moyenne $0,88 \pm 0,40$ des femelles avaient eu des petits. On a évalué que les moyennes géométriques ( \pm écart-type bootstrappé) pour les taux de croissance de la population à la structure d'âge stable étaient de 1,055 $\pm 0,011$ (sans prélèvements) et de 1,019 $\pm 0,015$ (avec prélèvements). La valeur estimée à partir du marquage-recapture, moyennée par le modèle, de l'abondance moyenne ( \pm 1 erreur-type), pour les années allant de 1994 à 1997 était de $2074 \pm 266$ ours, dont $1017 \pm 192$ femelles et $1057 \pm 124$ mâles. On a intégré les paramètres démographiques et leurs termes d'erreur dans une analyse des risques de prélèvements conçue pour tenir compte des incertitudes démographiques, de processus et d'échantillonnage lors du calcul des probabilités de persistance (c.-à-d. une analyse stochastique de la viabilité de la population qui tient compte des prélèvements). En se basant sur nos prélèvements estimés de l'ours polaire dans la baie de Baffin ( 88 ours/an), la probabilité que la population ne décline pas plus que ce qu'elle pourrait récupérer en 5 ans était de 0,95 , ce qui suggère que la chasse actuelle est durable.

\footnotetext{
${ }^{1}$ Department of the Environment, Government of Nunavut, P.O. Box 209, Igloolik, Nunavut X0A 0L0, Canada

${ }^{2}$ National Marine Mammal Laboratory, Alaska Fisheries Science Center, National Marine Fisheries Service, Seattle, Washington 98115 , U.S.A.

${ }^{3}$ Department of Biology, University of Saskatchewan, 112 Science Place, Saskatoon, Saskatchewan S7N 5E2, Canada

${ }^{4}$ Corresponding author: mcloughlin@sask.usask.ca

${ }^{5}$ Greenland Institute of Natural Resources, P.O. Box 570, DK-3900 Nuuk, Greenland

${ }^{6}$ Department of Resources, Wildlife, and Economic Development, Government of the Northwest Territories, Yellowknife, Northwest Territories X1A 2P9, Canada

${ }^{7}$ Current address: Fisheries and Oceans Canada, 501 University Crescent, Winnipeg, Manitoba R3T 2N6, Canada

${ }^{8}$ Current address: Arizona Game and Fish Department, WMRS 2221, West Greenway Road, Phoenix, Arizona 85023, U.S.A.

(C) The Arctic Institute of North America
} 
Mots clés: démographie, prélèvement, marquage-recapture, ours polaire, viabilité de la population, analyse, logiciel MARK, recrutement, survie, Ursus maritimus

Traduit pour la revue Arctic par Nésida Loyer.

\section{INTRODUCTION}

Stabilizing populations through sustained harvest is a basic application of wildlife management theory; in practice, however, it is exceedingly difficult to establish the correct composition (sex and age distribution) of sustainable yields. Traditional deterministic population models require considerable information to identify sustainable yields (Caughley, 1977), including the natural birth and death rates for different age/sex strata in the population, the shape of the relationship between population growth rate in the absence of harvest and population size, or parameters such as carrying capacity or intrinsic rate of increase. It is particularly important, however, that this information be provided with little or no error. If biologists are uncertain about input parameters, deterministic models of yield will fail to provide results applicable to the management of real populations. Since vital rates of actual populations are almost always obtained with some degree of error, either through sampling error or through observations of process variation (e.g., inter-year variation due to environmental stochasticity; White, 2000), deterministic attempts to calculate sustainable yield are only rarely of value for managing real populations.

Rather than relying upon deterministic models to establish sustainable yields, an alternative approach may be to manage for harvests that will provide a reasonable probability of population persistence for some time into the future. Models of probability of population persistence, such as stochastic population viability analysis (PVA), are ideal for incorporating parameter variation into harvest models, including demographic, environmental, and sampling variation (review in White, 2000). When information is uncertain, theoretically any harvest level poses some risk to a population. PVA has the flexibility to provide managers and stakeholders with a probability that a given harvest composition will be sustainable, but also with consequences (e.g., the length of moratorium required to restore the population) should a harvest later be deemed too severe (Taylor et al., 2002).

We used mark-recapture data collected from 1974 to 1997 to estimate the demographic characteristics of polar bears inhabiting Baffin Bay, Canada and Greenland (Fig. 1), and harvest risks for the population at its estimated size. Our demographic analysis includes a detailed assessment of age- and sex-specific survival and recruitment from 1221 marked polar bears, which used information contained within the standing age distribution of captures and survival and abundance estimates from markrecapture analysis. We incorporated demographic parameters and their error terms into a harvest risk analysis

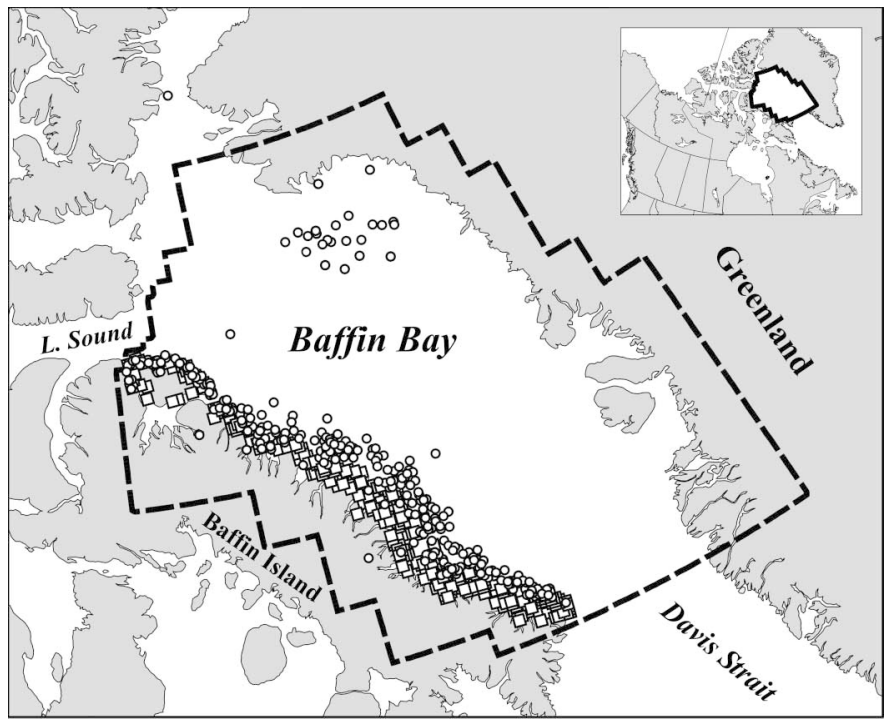

FIG. 1. The location of all captures and recaptures within the Baffin Bay polar bear population, northern Canada and Greenland. Boundaries are defined as in Taylor et al. (2001a). Spring captures from 1974 to 1993 are indicated by the symbol ( $\bigcirc$ ). Autumn (onshore) captures from 1993 to 1997 are indicated by the symbol ( $\square$ ).

designed to consider demographic, environmental, and sampling variation in generating likelihoods of persistence (i.e., a stochastic, harvest-explicit PVA). We provide estimates of probability of population persistence above a threshold of population decline for an array of harvest rates, but also the estimated numbers of years required for recovery of the population should a harvest strategy result in population decline below the stated threshold. We contrast the mark-recapture analysis presented in this study with an earlier analysis of the demography of polar bears in Baffin Bay to illustrate the value of recent advances in mark-recapture methodology.

\section{METHODS}

\section{Study Area}

The geographic bounds of the Baffin Bay polar bear population (Fig. 1) have been previously evaluated using movements of marked and recaptured (or harvested) individuals (Taylor and Lee, 1995), DNA analysis (Paetkau et al., 1999), and movements of radio-collared adult females (Taylor et al., 2001a). The Baffin Bay population is considered to be demographically discrete, but shared between Greenland and Canada. The total geographic area of the Baffin Bay population is approximately $1.03 \times$ $10^{6} \mathrm{~km}^{2}$. 
The distribution of polar bears in Baffin Bay is strongly influenced by the seasonal distribution of sea ice (Ferguson et al., 2000; Taylor et al., 2001a). Because of currents and prevailing winds in this part of the Arctic, sea ice remains longest each spring along the Baffin Island coast. As a result, almost every polar bear of the Baffin Bay population concentrates in spring near Baffin Island, being forced ashore for the open-water season (Taylor et al., 2001a). This feature of the Baffin Bay population greatly enhanced our efforts at uniform sampling of the population. Nondenning bears (i.e., males and non-parturient females) return to the sea ice in November (Ferguson et al., 1997), and many proceed across Baffin Bay to Greenland waters (but return west in spring, as sea ice disappears first from east Baffin Bay and Davis Strait). Most Baffin Bay polar bears do not move south except along the Baffin Island coast because of the open-water barrier caused by the West Greenland Current.

\section{Captures, Recaptures, and Recoveries}

Four main capture programs in Baffin Bay yielded the data used in this study. The first effort (1974-79) was incidental to a study of the Lancaster Sound population and occurred only from communities on northern Baffin Island. From 1980 to 1985, polar bears were captured as part of an independent demographic study on east-central Baffin Island. From 1989 to 1993, there were incidental captures in both Greenland and Canada associated with movement (radio-telemetry) studies. The most recent capture program was staged from 1994 to 1997, but with little effort in 1996. During 1974-93, capture sampling was conducted in spring (April-May) prior to breakup by searching shorefast ice along Baffin Island. Active pack ice was not searched because of difficulties in tracking and fuel limitations of search helicopters. During 1993-97, capture sampling was conducted in autumn (SeptemberOctober), during the open-water season, when all Baffin Bay polar bears were onshore. (Sampling took place during both seasons in 1993.) The coastal islands, coastal areas, and the interior of Baffin Island were systematically and uniformly searched in 1994, 1995, and 1997. All captures were opportunistic: every bear seen was captured (or recaptured).

We chemically immobilized all bears and their dependent cubs for capture and marking according to procedures described by Stirling et al. (1989), following Animal Care Protocol No. 950005 of the University of Saskatchewan and under guidance of the Canadian Council on Animal Care. Bears captured or recaptured prior to 1985 were immobilized primarily with Sernylan (Furnell and Schweinsburg, 1984); bears captured in later years were immobilized with Telazol (Stirling et al., 1989). We assigned a unique identification number to each bear upon its initial capture and marked the animals accordingly, using plastic ear tags and permanent lip tattoos. We also marked each bear with a wax crayon on the fur to ensure that it was not captured more than once per year. We considered a bear's age as "known" if the bear was captured as a cub-ofthe-year (cub) or yearling, or if its age was estimated by counting annular rings of an extracted vestigial premolar (Calvert and Ramsay, 1998). We recorded the sex, age, family status, and location of all polar bears killed by hunters, killed as problem bears, or found dead from any cause. We believe Greenland hunters reported most of their kill of marked bears (E.W. Born, pers. obs.).

\section{Reproduction}

Our estimates of reproductive parameters were developed from analysis of the standing age distribution of the population, and they focused on the Baffin Bay population structure during the largest and most recent capture program (1994-97). We determined the standing age distribution for the population based only on captures and recaptures that occurred inside the Baffin Bay boundary (Fig. 1). To acknowledge parental care, we based agespecific litter production rate on the number of females that had been available to mate the previous year (i.e., those females with no cubs or two-year-olds), rather than the total number of females. Our estimate of litter production rate assumed that females survived after mating. We included litter production rate for age 4 and age 5 to acknowledge potential subadult reproduction. We assumed that by age 6 , all females were producing litters at adult rates. Our methods for estimating litter production rates and litter size of cubs and yearlings are described in detail in Taylor et al. (1987a, 2000). The proportion of cubs (age 0 ) that were male was the binomial mean $\mathrm{M}: \mathrm{F}$ ratio based on the total number of age 0 cubs between 1994 and 1997.

We calculated an additional four summary reproductive parameters for the Baffin Bay population: mean reproductive (litter production) interval, mean annual reproductive rate, proportion of females that reached adulthood but had only one litter, and proportion of females that reached adulthood but produced no litters.

We used a jackknife method (Arveson, 1969) to obtain variances of reproductive parameters estimated from the standing age distribution (Taylor et al., 1987a, 2000). The data were collected over many years, so our estimates of variance included both sampling error and inter-year ecological variation. The variances of summary reproductive parameters were determined by means of Monte Carlo simulations with 1200 iterations, using the Visual Basic program "Vital Rates" (Taylor et al., 2000). The program is available from the senior author upon request.

\section{Survival and Abundance}

Estimates of survival and abundance were constructed from analysis of capture-recapture and recovery data using the Burnham Cormack-Jolly-Seber (CJS) model formulation implemented in Program MARK (White et al., 2000). The Burnham model (Burnham, 1993) incorpo- 
rates harvest recoveries of tagged animals into a CormackJolly-Seber model framework for capture-recapture data. The CJS likelihood for capture-recapture data is conditioned on initial capture events (i.e., the initial capture is treated as a release). The likelihood is based solely on recapture events of marked (i.e., previously caught) animals, and it is defined by user-specified models for survival $(S)$ and (re)capture probabilities $(p)$ that may be expressed as functions of covariates such as sex, age, and time. The Burnham model extends the CJS model to include a model for recovery (i.e., harvest) probabilities ( $r$ ) that may also include covariates.

We used Program MARK to analyze the capture-recapture and recovery data collected in Baffin Bay from 1974 to 1997 (through 1998 for recoveries). Captures of bears from 1974 to 1992 were used as initial captures, but recaptures were ignored during this period because captures were generally restricted to a local subset of the entire population. We used recaptures only from 1993 to 1997, when extensive autumn capturing was conducted. Recoveries of harvested bears were assumed to occur between captures; however, since our capture efforts typically spanned a period of two months, there may have been some overlap between harvesting and capturing. We treated spring harvest as if it occurred before spring captures and after autumn captures of the previous year. Eighty-eight percent of bear harvests occurred between October and April, and 95\% of captures were in April-May and September-October. Thus, harvest recoveries for year $i+1$ included autumn harvest recoveries from year $i$ and spring harvest recoveries from year $i+1$. We fixed the fidelity parameter $(F)$ at 1.0; that is, we assumed no permanent emigration from Baffin Bay and complete overlap of the population sampled by capture and harvesting, which was likely with autumn captures. We used all recaptures and harvest recoveries of Baffin Bay bears, even if they occurred outside the boundaries of the Baffin Bay population.

We identified a priori a limited number of parameter sets (models) consistent with our sampling effort. For the pooled 1974-97 data, we examined a series of models for capture probability $(p)$ that incorporated potential covariates for our system. We expected that capture probability would vary by year because conditions were different each year, although the amount of capture effort was approximately the same for 1994,1995 , and 1997 . Therefore, we considered a model that allowed capture probability to vary for each year ( $\left.p_{\text {year }}\right)$ and a null model in which capture probability did not vary between years. Bears were located by visual observation and tracking from a helicopter, and successful location and eventual capture were likely affected by the number of bears in a group, their reaction (if any) to the capture helicopter, and their movement patterns and fidelity to known high-use areas. Because these factors were likely to vary for different classes of family status, we categorized bears into three classesfemales, cubs, and yearlings; subadults $(2-4$ years) of either sex; and adult males - and considered models in which capture probability varied for these classes ( $\left.p_{\text {family }}\right)$. We also considered models $\left(p_{\text {radio }}\right)$ in which bears with transmitters (radios) possessed a different and most likely higher capture probability because their location was known at various times throughout the year. Cubs and yearlings of a female with a transmitter were considered to have the same probability of capture as their mother.

For survival probability $(S)$, we considered models that included sex, age, and season of mark deployment (spring or autumn) as covariates ( $S_{\text {sex }}, S_{\text {age }}$, and $\left.S_{\text {season }}\right)$. Males were more likely to be harvested, so we considered sex as a potential covariate of survival. Survival was also likely to vary by age; in particular, we expected cubs to have lower survival than non-cubs. We structured age into four classes: 1) cubs, 2) yearlings/sub-adults ( $1-4$ years), 3 ) adults (520 years), and 4) senescent adults (21+ years). Although annual differences in harvest and environmental conditions could potentially create annual variation in survival, we did not consider models with annual survival rates because we could not reliably estimate separate rates for 1974-92, when we did not recapture bears and there were too few recoveries. We expected that survival might have been lower for bears marked in spring (1974-92) than for those marked in autumn, because bears that used shorefast ice during spring would be vulnerable to harvest in both spring and autumn, whereas those marked in the autumn would include bears that did not use shorefast ice in spring (and would thus be less vulnerable to harvest).

We used the same sub-model for survival $(S)$ and recovery probabilities $(r)$, on the assumptions that harvest was a primary source of mortality and natural mortality was relatively constant. In the MARK implementation of the Burnham CJS model, $r$ is the probability that a dead marked bear is recovered and reported. We have included only recoveries of harvested bears, so if all harvests of marked bears were reported, $r$ represents the proportion of mortality due to harvest. If all harvested marked bears were reported, then the probability that a bear would be harvested was $(1-S) r$.

We fitted a series of models using each capture probability sub-model with each survival/recovery probability sub-model. We considered additive models with main effects (e.g., $S / r_{\text {sex }}+$ age + spring,$p_{\text {year }+ \text { family }+ \text { radio }}$ ), but we limited our analysis to relatively simple interactions (e.g., $\left.\mathrm{S} / \mathrm{r}_{\text {sex } \times \text { age }}\right)$ because data were insufficient to support more complex models. For model selection, we used Akaike's Information Criterion adjusted for overdispersion $\left(\mathrm{QAIC}_{c}\right.$, Burnham and Anderson, 2002). The data were likely to be overdispersed (i.e., greater than binomial variation) because survival and capture events of family groups (i.e., females with cubs or yearlings) were not independent. Various approaches for estimating the overdispersion coefficient $(\hat{c})$ have been suggested (Lebreton et al., 1992; White et al., 2000). Overdispersion can occur if fates (survival, capture) are linked. McCullagh and Nelder (1991:125) showed that the overdispersion coefficient is bounded above by the cluster (group) size for a population 
in equal-sized clusters in which the binomial response varies by cluster. However, this approach could overestimate $\hat{c}$ if group composition changes over time so that fates are not linked. Mother-cub pairs are a clear example of linked fates: cub survival is highly dependent on the mother's survival, and a cub will only be recaptured as a yearling with its mother. While the survival of a yearling may depend somewhat on its mother's survival, yearlings were not likely to be recaptured with their mothers as twoyear-olds. Therefore, we estimated $\hat{c}$ as the ratio of total bears captured during 1993-97 to non-cubs captured during the same period. This method effectively treated the sample size as the number of non-cub captures. We used $\hat{c}$ to compute $\mathrm{QAIC}_{c}$ and to inflate variance estimates.

Because the Burnham-CJS model likelihood does not include the probability distribution for unmarked animals, it may not be optimal (i.e., of highest precision) for estimating abundance. However, at present we are unaware of any model that has been developed to include recoveries in a Jolly-Seber model formulation with a probability distribution for first captures. We followed the approach of McDonald and Amstrup (2001) and Taylor et al. (2002) in constructing abundance estimates. We used estimated recapture probabilities $\left(p_{i}\right)$ in year $i$ from animals marked prior to year $i$ with the number of captures and recaptures in year $i$ to estimate abundance $\left(N_{i}\right)$, for each year. We computed variance estimates for $N_{i}$ using a Taylor series approximation (Seber, 1982) (also known as the delta method) that contains a component of variance for the number of marks observed and another for estimation of $p$ (Taylor et al., 2002). For cases where we stratified the population into $k$ strata (e.g., family class), the total estimated population was the sum of stratum estimates and the variance estimator was extended to include covariances between estimated capture probabilities in the $k$ strata (see Taylor et al., 2002). We used a similar estimator to construct a variance estimate for the average population size over several years.

Our estimates of total survival $(S)$ derived from capturerecapture data, included losses from harvest. We were interested in estimating natural survival $\left(S_{n}\right)$ to investigate potential impacts of alternative harvest strategies. Unfortunately, total harvest of Baffin Bay bears from Greenland was uncertain, so we could not use the approach of Taylor et al. (2002) to estimate natural survival. Instead, we used the following estimator:

$$
S_{n}=S+(1-S) r
$$

This estimator assumes that all harvested, marked bears were recorded. Thus it may underestimate natural survival if harvest of marked bears is underreported. But its advantage, compared to the estimator of Taylor et al. (2002), is the constraint that $S_{n}$ cannot exceed 1.0. Here, we also used a Taylor series approximation for the variance of natural survival:

$\operatorname{Var}\left(S_{n}\right)=\operatorname{Var}(S)(1-r)+\operatorname{Var}(r)(1-S)^{2}+2 \operatorname{Cov}(S, r)(1-S)(1-r)$
Variances and covariances for $p, S$, and $r$ were computed by Program MARK after inflation by the overdispersion coefficient.

\section{Population Growth Rate}

The geometric mean, zero-harvest population growth rate $\left(\lambda_{N}\right)$ and harvested population growth rate $\left(\lambda_{H}\right)$ at stable age distribution were calculated according to Taylor et al. (1987b, 2001b). We ran 1200 Monte Carlo simulations to estimate the geometric mean of $\lambda$ using the life tablebased Visual Basic program 'RISKMAN' (Taylor et al., 2001b; McLoughlin et al., 2003; McLoughlin and Messier, 2004) presented in the section on Harvest Risk Analysis. We described variability about $\lambda$ by presenting the bootstrapped standard deviation (SD) of $\lambda$ (Manly, 1997).

\section{Harvest Risk Analysis}

The typical metric for population viability analysis (PVA) is mean likelihood of extinction or quasi-extinction (i.e., effective extinction) over a set period of time (White, 2000). However, most managers of harvested populations are not concerned about extinction, but rather about the risk that overharvesting will reduce population numbers. The management goal is typically to maximize harvest opportunities for current hunters without placing the population and the interests of future generations at risk. We used stochastic methods of PVA (e.g., Monte Carlo simulations) to explore harvest management options for Baffin Bay polar bears by estimating the risk of depletion for a number of harvest scenarios. For this analysis, we considered a population "depleted" if its size at the end of the trajectory was below a threshold proportion $(T)$ of the initial population size that would not allow recovery within a specified number of years if the harvest were to be discontinued through a moratorium. We computed the expected years to recovery $(Y)$ from a reduced population size $\left(N_{R}\right)$ to a target size $\left(N_{T}\right)$, in this case, initial population size, using the unharvested population growth rate $\left(\lambda_{N}\right)$ :

$$
Y=\frac{-\ln (P)}{\ln \left(\lambda_{N}\right)}
$$

where $P=N_{R} / N_{T}$. The threshold proportion $(T)$ for a specified recovery time $(Y)$ was calculated as:

$$
T=e^{-Y \ln \left(\lambda_{N}\right)}
$$

A population reduced to $P \geq T$ could be expected to recover to its original size within $Y$ years if the harvest were stopped (i.e., by a harvest moratorium). A population reduced to $P<T$ would not be expected to recover to its original size within $Y$ years even if the harvest were stopped, which we defined as an unacceptable outcome. This model conservatively assumes that at discontinuation 
of harvest, the natural (unharvested) rate of increase would not be higher than that observed at the start of simulation. Increasing harvests could, however, lead to decreased negative effects of density-dependence (i.e., a higher unharvested rate of increase), for example, through increased reproduction or changes to age and sex distribution. We felt that harvest risk levels using recovery times, rather than fractions of the initial (original) population remaining, would make consequences of overharvest more intuitive to managers and the hunting communities they serve.

RISKMAN (Taylor et al., 2001b) was used to estimate the proportion of acceptable outcomes (i.e., trajectories that did not reduce the population below $T$ ) for a range of recovery times from 1 to 25 years. RISKMAN differs from other simulation models in providing the option to model the specific population dynamics of species with multiyear reproductive schedules, such as bears, cetaceans, elephants, phocids, and primates (Taylor et al., 1987b), although RISKMAN can also model simple annual reproduction. Here we modeled age-specific recruitment rate as a function of three components: the availability $(A)$ of a female to mate at age $x-1$ and produce offspring in year $x$, the litter production rate of reproducing females $(B)$, and the litter size of newborns $(L)$. Our definition of age-specific recruitment rate $\left(m_{\mathrm{x}}\right)$ was:

$$
m_{\mathrm{x}}=A_{\mathrm{x}-1} \cdot B_{\mathrm{x}-1} \cdot L_{\mathrm{x}}
$$

RISKMAN allows the population to be structured into any number of age classes with the following sex and family-status categories: males; females with no young; females with 1, 2, or 3 newborns; females with 1,2, or 3 yearlings; and females with 1, 2, or 3 two-year-olds. The model incorporates a minimum and maximum age of reproduction. In addition to age- and sex-specific reproduction, age- and sex-specific survival, including maximum age of life $(w)$, is a required input to the model, used to compute age-specific survivorship $\left(l_{x}\right)$. We calculated the population growth rate from the net reproductive rate

$$
\left(R_{0}=\sum_{x=0}^{w} l_{x} m_{x}\right),
$$

(the average number of offspring produced per individual per lifetime), and generation length (Caughley, 1977).

RISKMAN incorporates stochasticity into its population model at several levels. To incorporate uncertainty in initial population size, simulations can be generated using a random initial population size $\left(N_{T}\right)$ drawn from a normal distribution, with mean and standard error (SE) provided by the user. For each year of simulation, RISKMAN obtains a random normal deviate for each survival and recruitment rate based on user-specified means and SEs for particular sex and age strata. Individuals in the model are then exposed in a series of Bernoulli trials to the probabilities described by annual random deviates. This process can incorporate annual variability and sampling error, but also the uncertainty associated with applying the random mean to individual trials, which result in either success or failure (e.g., survival or death; a litter or failure to produce a litter). Stochasticity in litter size and sex ratio can also be incorporated into the model. RISKMAN uses Monte Carlo techniques to generate a distribution of results (Manly, 1997), and then uses this distribution to estimate the variance of summary parameters, such as population size at a future time, population growth rate, and the proportion of runs that result in a population decline set at a predetermined level by the user. We adopted the latter to evaluate threshold proportions $(T)$ for specified recovery times $(Y)$. RISKMAN is available upon request from the senior author.

Our scenarios were specific for a monitoring interval of 15 years beginning in 1998 . We chose 15 years as a simulation interval because we estimated that about $10 \%$ of the Baffin Bay population would still be marked after 15 years. Adult survival rates are underestimated when there are no observations of old marks in the population (i.e., no observations of long life; M.K. Taylor, unpubl. data), so we decided that our inventory monitoring cycle should not exceed 15 years.

The proportion of acceptable outcomes was examined for a range of annual harvest levels $(40-180$ bears/yr) that were within the range of harvests likely to be experienced by Baffin Bay polar bears (the historical annual kill for Baffin Bay from 1970 to 1999 was estimated to average 88 bears per year; see Results). The frequency of occurrence of acceptable outcomes (based upon the threshold value, $T$ ) was monitored and reported as the cumulative proportion of successful runs over time. It was possible for a simulated population to decline to an unacceptable number and then increase back to an acceptable number before 15 years had elapsed. The cumulative frequency of acceptable values ranged between 0.0 and 1.0 and depended on the starting population number, the survival and recruitment rates, the harvest sex and age composition, the harvest number, and the uncertainty of these parameters (all obtained from the previous standing age and markrecapture analyses). The unharvested population growth rate determined the minimum time required for recovery from any given reduction in numbers, and we stated this as the proportion of original numbers required for recovery times of $1,5,10,15,20$, and 25 years in the absence of further harvest.

For each year of the simulation, RISKMAN estimated the mean and SE associated with total population size, number of males, number of females, proportion of females in the harvest, population growth rate, and other summary parameters. For our risk analysis, we identified the initial age distribution by determining the stable age distribution, using total mortality values. The harvest selectivity-vulnerability array was identified by comparing the total mortality stable age distribution with the sexage-family status distribution of the historical harvest (Taylor et al., 2002). The harvest sex-age-family status 
TABLE 1. Initial captures of unmarked polar bears classified by age and sex for 1974-92, 1993-95, and 1997. In parentheses, we present numbers of bears recaptured at least once in the years 1993-95 and 1997, followed by the number of bears recovered in the harvest during the harvest years 1975-99. Bears initially caught in 1997 had no chance of recapture (indicated by an asterisk), although they could have been harvested in 1997 and 1998.

\begin{tabular}{|c|c|c|c|c|c|c|}
\hline Sex & Year & Cub & $1-4$ yr old & $5-20 \mathrm{yr}$ & $20+y r$ & Total \\
\hline \multirow[t]{5}{*}{ Female } & $1974-92$ & $52(2,11)$ & $73(10,26)$ & $126(12,31)$ & $3(1,1)$ & $254(28,69)$ \\
\hline & 1993 & $15(2,3)$ & $22(2,5)$ & $30(4,2)$ & $1(0,0)$ & $68(8,10)$ \\
\hline & 1994 & $26(6,1)$ & $25(5,2)$ & $42(7,2)$ & $1(0,0)$ & $94(18,5)$ \\
\hline & 1995 & $16(0,4)$ & $34(5,3)$ & $37(5,1)$ & $2(0,0)$ & $89(10,8)$ \\
\hline & 1997 & $22(*, 0)$ & $22(*, 0)$ & $38(*, 0)$ & $0(*, 0)$ & $82(*, 0)$ \\
\hline Total & & $131(10,19)$ & $176(22,36)$ & $273(31,36)$ & $7(1,1)$ & $587(64,92)$ \\
\hline \multirow[t]{5}{*}{ Male } & $1974-92$ & $52(2,16)$ & $67(8,33)$ & $81(7,26)$ & $4(0,0)$ & $204(17,75)$ \\
\hline & 1993 & $12(0,0)$ & $21(11,5)$ & $41(18,7)$ & $3(1,0)$ & $77(30,12)$ \\
\hline & 1994 & $16(4,0)$ & $25(9,4)$ & $52(14,6)$ & $7(0,0)$ & $100(27,10)$ \\
\hline & 1995 & $19(0,4)$ & $43(6,3)$ & $51(6,7)$ & $3(1,1)$ & $116(13,15)$ \\
\hline & 1997 & $19(*, 0)$ & $32(*, 5)$ & $86(*, 3)$ & $0(*, 0)$ & $137(*, 8)$ \\
\hline Total & & $118(6,20)$ & $188(34,50)$ & $311(45,49)$ & $17(2,1)$ & $634(87,120)$ \\
\hline
\end{tabular}

TABLE 2. Estimates of the mean and standard error of reproductive parameters of polar bears inhabiting Baffin Bay, 1994-97.

\begin{tabular}{lcc}
\hline \hline Parameter & Mean & SE \\
\hline Cub litter size & 1.59 & 0.07 \\
Yearling litter size & 1.63 & 0.07 \\
Litter production rates for age 4 & 0.10 & 0.12 \\
Litter production rates for age 5 & 0.88 & 0.40 \\
Litter production rates for age 6+ & 1.00 & 0.17 \\
Percentage of newborns that are male & 0.49 & 0.03 \\
Reproductive interval (years) & 2.55 & 0.14 \\
Reproductive rate (litters/year) & 0.39 & 0.02 \\
Proportion of females with only one litter & 0.12 & 0.07 \\
Proportion of females with no litters & 0.05 & 0.03 \\
\hline \hline
\end{tabular}

distribution was stratified by sex, age (cubs and yearlings, ages $2-4$ years, ages $5-20$ years, and ages $21-30$ years), and family status (alone, with cubs and yearlings, with two-year-olds). Harvest simulations were conducted using the natural survival rate estimates (mark-recapture analysis) and recruitment data (standing age analysis) from this study; the harvest age and sex distribution for Baffin Bay polar bears detailed in the 2001 Canadian Federal and Provincial Polar Bear Technical Committee (PBTC) status report (PBTC, 2001); and recovery rates of marked animals. For starting population size (and SE), we used the 1994-97 population estimate obtained from markrecapture analysis.

\section{RESULTS}

\section{Captures, Recaptures, and Recoveries}

Of 587 female and 634 male bears marked between 1974 and 1997, 64 females and 87 males were recaptured at least once (Table 1). Of the 172 recaptures during $1993-$ 97, 49 were recaptures of radio-collared female bears or their accompanying young. In addition, 212 marked bears (92 females and 120 males) were recovered as dead bears during 1974-98. These were largely legal kills made for sport, for subsistence, or in the defense of life or property.

\section{Reproduction}

Summary reproductive parameters for the Baffin Bay polar bear population based on analysis of the standing age distribution for captures (1994-97) are presented in Table 2.

\section{Mark-Recapture Analysis}

Of the 935 total bear captures and recaptures from 1993 to 1997,145 involved cubs; hence, we used a value of $\hat{c}=$ 1.18 for overdispersion in our mark-recapture analysis (i.e., one plus the ratio of cub captures to non-cub captures). The lowest $\mathrm{QAIC}_{c}$ model $\left(S / r_{\mathrm{age}}+\mathrm{sex}+\right.$ season,$p_{\text {radio }+}$ family) included additive effects of age, sex, and marking season on survival and recovery. Capture probability was constant across time (1993-97) but varied across family classes, and our use of radio locations made capture almost certain for radio-collared females (Table 3 ). The next three models with the lowest $\triangle \mathrm{QAIC}_{c}$ values (Table 3) were sufficiently close that model averaging was indicated (Burnham and Anderson, 2002), and we included these models with the primary model in a weighted average to present survival and abundance estimates.

Estimates of model coefficients provide for interpretation of covariate effects (Table 4). The probability of autumn recapture was lower for females and yearling cubs than for adult males and subadults, except for radiocollared females and their young. The estimated recovery rate was highest for subadults and males, the two age-sex strata most likely to be harvested. Cubs and older bears $(21+)$ were least likely to be hunted. Survival rate was lower for bears caught in spring than for bears caught in autumn, likely as a result of higher harvest rates for springcaught bears.

We present model-averaged survival estimates only for bears marked in autumn (Table 5). This group is more 
TABLE 3. $\triangle$ QAIC $_{c}$ values for models fitted to capture-recapture and harvest recovery data for polar bears in Baffin Bay (1974-97). Covariates of the survival/recovery model included age and sex of bears and season of recovery (autumn or spring). Covariates of the capture probability model included age and sex of captured animals, year of capture or recovery, and whether or not the animal was wearing a radio transmitter (radio). The number of estimated parameters for each sub-model is shown in parentheses. Values in bold type represent models used in model averaging.

\begin{tabular}{lcccc}
\hline \hline & & \multicolumn{2}{c}{ Capture Probability Model $(p)$} \\
\cline { 2 - 4 } Survival/Recovery Model $(S / r)$ & radio $(1)$ & radio + year $(4)$ & radio + family (3) & radio + family + year (6) \\
\hline age + season (10) & 9.75 & 12.69 & 7.26 & 10.72 \\
age + sex + season $(12)$ & $\mathbf{3 . 5 4}$ & 6.72 & $\mathbf{0}$ & $\mathbf{3 . 7 2}$ \\
age $\times$ sex + season $(16)$ & 8.01 & 11.01 & $\mathbf{4 . 2 7}$ & 7.93 \\
\hline \hline
\end{tabular}

TABLE 4. Estimates and standard errors (SE) of logit parameters

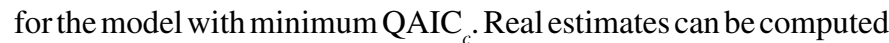
with the inverse logit: $\exp (x) /(1+\exp (x))$. Each effect is additive in relation to the intercept. For example, $x=0.448+1.840-0.307$ for survival of one- to four-year-old males. The SE for the radio effect was not reliable because the parameter was at a boundary $(p=1.0)$. An estimate divided by its SE can be treated as an approximate $t$-value in a significance test that the estimate is non-zero (Burnham and Anderson, 2002).

\begin{tabular}{llrrr}
\hline \hline Sub-model & \multicolumn{1}{c}{ Logit Coefficient } & Estimate & SE & Estimate/SE \\
\hline \multirow{2}{*}{ Survival } & Intercept (Female cub) & 0.448 & 0.365 & 1.2 \\
& $1-4$ & 1.840 & 0.477 & 3.9 \\
& $5-20$ & 2.339 & 0.334 & 7.0 \\
& $21+$ & 1.868 & 0.492 & 3.8 \\
& Male & -0.307 & 0.189 & -1.6 \\
& Spring & -0.718 & 0.293 & -2.4 \\
Recovture & Intercept (Male adult) & -1.560 & 0.152 & -10.2 \\
& Radio & 21.760 & $\mathrm{~N} / \mathrm{A}$ & $\mathrm{N} / \mathrm{A}$ \\
& Adult female + yr & -0.648 & 0.222 & -2.9 \\
& $1-4$ & -0.429 & 0.245 & -1.8 \\
& Intercept (Female cub) & -2.973 & 0.443 & -6.7 \\
& $1-4$ & 2.479 & 0.669 & 3.7 \\
& 5-20 & 1.723 & 0.388 & 4.4 \\
& 21+ & 0.358 & 0.578 & 0.6 \\
& Male & 0.474 & 0.228 & 2.1 \\
& Spring & 0.677 & 0.341 & 2.0 \\
\hline \hline
\end{tabular}

representative of the entire population because it includes those bears that did not frequent shorefast ice in spring. The clearest age and sex difference was between cub and non-cub survival. While the model included possible senescence (survival estimates were lower for bears aged 21 years or more than for other non-cub classes), the survival rate of bears in the oldest age class was within $1 \mathrm{SE}$ of the rate for bears aged 5-20 years (Table 5). Similarly, survival rates were not substantially different for males and females (Tables 4 and 5), but harvest recovery rates were substantially higher for males than for females (Table 4). The estimated natural survival rates for males and females 5-20 years old also differed by less than 1 SE (Table 4).

The model-averaged, mark-recapture estimate of mean abundance for years 1994-97 was 2074 bears $(\mathrm{SE}=266)$, which included 1017 females $(\mathrm{SE}=192)$ and 1057 males $(\mathrm{SE}=124)$. Females of age 5 years or more averaged 524 $(\mathrm{SE}=108)$ individuals. The total number of cubs in the population was estimated to be $387(\mathrm{SE}=82)$, giving an average natality of 0.74 cubs per adult female.
TABLE 5. Mark-recapture estimates of survival for the Baffin Bay polar bear population, 1994-97 (autumn-marked bears only). The upper rows present the mean and SE of natural survival (no harvest) for the various sex and age categories, and the lower rows, those of actual survival (including harvest mortality).

\begin{tabular}{lllllllllll}
\hline \hline & \multicolumn{3}{c}{ Female Survival Rate } & & \multicolumn{4}{c}{ Male Survival Rate } \\
\cline { 2 - 3 } \cline { 8 - 10 } & Cub & $1-4$ & $5-20$ & $21+$ & & Cub & $1-4$ & $5-20$ & $21+$ \\
\hline Mean & 0.620 & 0.938 & 0.953 & 0.919 & & 0.570 & 0.938 & 0.947 & 0.887 \\
SE & 0.095 & 0.042 & 0.020 & 0.046 & & 0.094 & 0.045 & 0.022 & 0.060 \\
& & & & & & & & & & \\
Mean & 0.600 & 0.901 & 0.940 & 0.913 & & 0.538 & 0.879 & 0.923 & 0.874 \\
SE & 0.096 & 0.045 & 0.021 & 0.047 & & 0.094 & 0.049 & 0.024 & 0.062 \\
\hline \hline
\end{tabular}

\section{Population Growth Rate}

Using mark-recapture survival rates and reproduction data, our bootstrapped estimate of the geometric mean unharvested, stable age population growth rate $\left(\lambda_{N}\right)$ was $1.055(\mathrm{SD}=0.011)$. Assuming the 1970-99 average annual Canadian harvest of Baffin Bay polar bears (66 bears/yr), and the probable recovery of marked polar bears by Greenland hunters ( $15-25$ bears/yr: we used 22 bears/ $\mathrm{yr}$ as an average), we estimated the geometric mean harvested, stable age population growth rate $\left(\lambda_{H}\right)$ to be 1.019 $(\mathrm{SD}=0.015)$.

\section{Harvest Risk Analysis}

The proportion of outcomes for the range of simulated harvest levels (40-180 bears/yr) and range of recovery times (1-25 yrs) for the Baffin Bay population are provided as a smoothed contour map (Fig. 2). Higher harvest rates constituted increased risk (fewer acceptable outcomes) to the population. If managers and stakeholders are willing to accept long periods (e.g., decades) of harvest moratorium should a harvest threshold be exceeded, the proportion of acceptable outcomes increases. To take an example using the estimated harvest of polar bears in Baffin Bay ( 88 bears/yr), the probability that the population would either increase or decline no more than could be recovered in five years was 0.95 . That is, $95 \%$ of the time, the population was not expected to decline below that proportion of the starting population required, given our estimate of natural (i.e., unharvested) population growth 


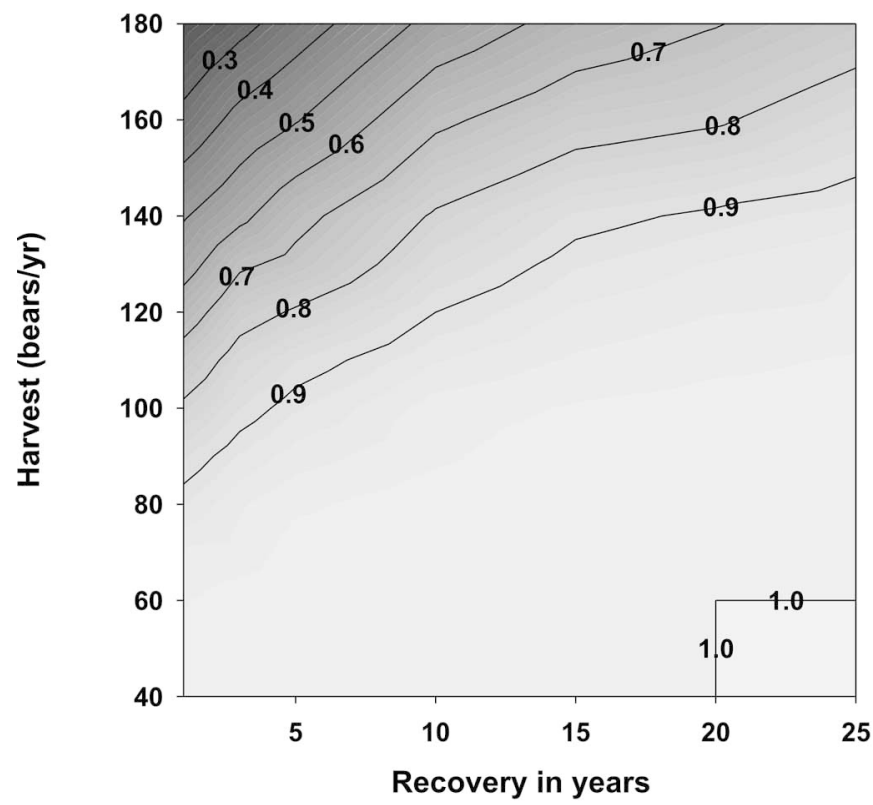

FIG. 2. The proportion of acceptable simulation outcomes (contour values) for a range of recovery times ( $1-25$ years) and a range of annual harvest values (40-180). "Acceptable" in this context means that in a given simulation run, the population did not decline to a level that would require more than $x$ years to recover.

rate $\left(\lambda_{N}=1.055\right)$, to recover to the original population size (2074 bears) within five years. The likelihood that the population might require more than five years to recover was 0.05 (i.e., 1 minus 0.95 ). If the harvest was raised to 120 bears per year, the chances that the population would either increase or decline no more than could be recovered in five years was reduced to approximately 0.81 (Fig. 2).

\section{DISCUSSION}

Observed natural (i.e., unharvested) survival rates and reproductive parameters for polar bears in Baffin Bay were generally higher than those obtained for adjacent populations of polar bears, suggesting that the Baffin Bay population is below carrying capacity and relatively vigorous. The unharvested finite rate of increase $\left(\lambda_{N}=1.055\right)$ the summary parameter combining data on natural survival and reproduction-was higher than that estimated (using the same methods presented here) for polar bears in Kane Basin to the northeast $\left(\lambda_{N}=1.009\right)$ and in Lancaster Sound $\left(\lambda_{N}=1.030\right)$ and Norwegian Bay $\left(\lambda_{N}=1.011\right)$ to the northwest (M.K. Taylor, unpubl. data). Only the unharvested population growth rate for polar bears in Viscount Melville Sound ( $\lambda_{N}=1.059$; Taylor et al., 2002), a population reduced substantially below carrying capacity by years of overharvest, was higher than the unharvested finite rate of increase of Baffin Bay polar bears. It is difficult to compare parameters presented in this study with those of other polar bear populations because of different methods and different terminology (Stirling et al., 1980, 1999; Ramsay and Stirling, 1988; Derocher and
Stirling, 1992, 1995; Amstrup, 1995). Further, few researchers have been able to estimate the rates of natural survival necessary for useful ecological comparisons (e.g., life history comparisons). However, our estimates of reproductive parameters (e.g., litter size and timing of first reproduction) fall within the general range of published values. Taylor et al. (2002) present a comprehensive comparison of vital rates among studied polar bear populations.

Taylor et al. (2002) suggested that previous estimates of vital rates and abundance for polar bears may have been compromised by the failure to incorporate heterogeneity into capture probabilities. Our earlier attempt to quantify the abundance of polar bears in Baffin Bay likely failed in this respect. Using mark-recapture data from 1980 to 1985, abundance was initially estimated (M.K. Taylor, unpubl. data) using a variety of open Jolly/Seber methods (Jolly, 1965; Seber, 1965; Pollock et al., 1990). At that time, we had yet to define population bounds for Baffin Bay polar bears (Taylor et al., 2001a) and relied only on spring-caught (i.e., on-ice) bears. Our earlier estimates of abundance for bears in Baffin Bay were markedly lower than those presented here. The highest estimate for the period 1980-85 was 937 bears $(\mathrm{SE}=265)$. This estimate of population size indicates that the quotas established during the late 1980s and 1990s were likely made in error. The quotas were developed against the advice of Inuit hunters, who felt that the population on which quotas were based was much larger than estimated.

Following the recommendation of local hunters, we conducted our most recent mark-recapture inventory in autumn (1994-97), when bears were on shore at Baffin Island. We were able to satisfy assumptions of a more flexible analysis model, and our estimate of abundance was considerably higher (i.e., 2074 bears, SE $=266$ ). By capturing every bear we encountered during autumn, we eliminated the limitation of previous sampling efforts conducted only in spring months, when most of the population was distributed on active pack ice and unavailable to capture teams. Our best information suggests that discrepancies in estimated abundance between the 1980-85 and 1994-97 studies were not the result of rapid population growth between census periods. Traditional ecological knowledge suggested stability in the population from 1985 to 1994 (M.K. Taylor, unpubl. data); data presented here suggest that from 1994 to 1997 the population was stable or slightly increasing $\left(\lambda_{H}=1.019\right)$.

As expected (Taylor et al., 2002), all of the top models (Table 3) included the radio-collar covariate (or being associated with a radio-collared bear) as an important predictor of capture probability. Female polar bears equipped with radio-collars and their cubs were more likely to be recaptured than other bears. Some bears were located and recaptured using radio signals; however, even after radio-collars were removed, these females and their cubs continued to have a higher probability of recapture than other bears. Behavioural preference of radio-collared bears for geographic areas where individuals are more 
easily observed (and thus captured), e.g., their affinity to landmarks and the sea coast, is one possible explanation of this result.

Analyses of other populations had led us to anticipate sex and age stratification for survival probability of cubs (age 0), subadults (age 1-4), adults (age 5-19), and older adults (age 21+); however, the only clear differences were lower survival for cubs and for bears caught in spring, and higher harvest recovery rates for males, prime-aged bears, and bears caught in spring (Tables 4 and 5). Lower survival rates and higher harvest recovery rates for bears marked in spring were consistent with previous findings that bears captured in spring represent a portion of the Baffin Bay population that is more susceptible to harvest (M.K. Taylor, unpubl. data). Our failure to demonstrate a decline in survival of older bears was likely due to insufficient sample size.

The population number $(N>2000)$ imposes an obvious constraint on the capture sample size, and small recapture samples relative to actual population size may limit analysis to models with fewer parameters. Data presented here were the result of a capture-recapture program spanning three decades, with a large effort exerted during the autumn captures of 1994-97. Even with the dedicated autumn onshore program, however, recapture probabilities ranged from 0.11 to 0.17 for bears without radio-collars. Faced with sample size limitations, it is essential to incorporate all sources of data into an analysis. By including harvest recoveries, we were able to double the number of bears "recaptured" after their initial release, which enabled us to derive more precise estimates of survival and abundance for risk assessment and management advice. However, we have yet to use our data to their fullest extent because we did not incorporate recoveries of unmarked bears or first captures of unmarked bears. At present, there are no models or software programs that provide a joint analysis of recovery-captures/recaptures using the first encounter (capture/harvest). Development of a more general model within a cohort framework is currently being investigated.

A stable harvested population growth rate, together with a relatively high unharvested population growth rate, suggests polar bears in Baffin Bay are being sustainably harvested below food carrying capacity; however, the existing harvest still presents some risk to the population. Our fieldwork was carried out in collaboration with local hunters, and it was immediately apparent that hunters were very adept at locating and harvesting polar bears. Although the study area was large and density of polar bears relatively low, local hunters maintained high success rates in all years. This hunt was legal and within the quota limitations set by the Governments of Greenland and Nunavut, Canada. Although we were able to document that the current harvest rate $(60-80$ bears/yr) is likely sustainable, our information also suggests that there is no safe maximum sustainable harvest rate for this population. Our risk assessment is simply an expression of uncertainty in the demographic parameters on which it is based. The RISKMAN simulations indicated that even though the estimated population growth rate in the absence of harvest was high, the population is at some risk even if the annual harvest policy is low (Fig. 2).

We believe our harvesting simulations are much more realistic than a deterministic calculation of maximum sustained yield that does not consider the uncertainty of underlying information. Both managers and stakeholders must recognize that scientific information rarely provides exact and absolutely correct harvest rate or quota values. Researchers have a responsibility to quantify the uncertainty of their measurements, and also the uncertainty of their management recommendations. Reporting scientific results in this manner is not only more honest; it also identifies the distribution of solutions where local and traditional knowledge may be used to make final determinations.

A potential problem with our harvest analysis is that our estimated take of bears by Greenland hunters (18-25 bears/year), which was derived from recovery probabilities of marked bears, is lower than the number of bears reported as harvested in Greenland. In some years, systematic polar bear harvest surveys were undertaken by the Greenland Home Rule Government (E.W. Born, pers. obs.). Although the sex and age composition of the Greenland harvest was not recorded during these surveys, the estimated harvest was approximately 72 bears per year (E.W. Born, unpubl. data). The large discrepancy between this estimate of Greenland's hunt and the estimate from the harvest of marked bears raises some concerns. It is possible our sampling protocol was biased in undersampling bears that, for whatever reason, were more susceptible to Greenland harvest, or that Greenland overreported kills in their surveys (e.g., if two or more hunters who shared a kill reported it independently when surveyed). Our own simulations show that if the Greenland kill were indeed 72 bears/year (i.e., combined Greenland/Nunavut take is 138 bears/year), the population would be declining $\left(\lambda_{H}=0.974\right.$, $\mathrm{SD}=0.041$ ), and a lengthy moratorium would be required to allow the population to recover from this decline (Fig. 2). However, Baffin Bay hunters have been emphatic that the population is increasing, which is consistent with our simulations. We suggest that confidence in polar bear conservation decisions would be enhanced by more systematic collection of Greenland's harvest data.

Until the Greenland kill can be verified and confirmed, our management recommendations must remain qualified. Management decisions must also consider the long-term goals for the population and the resources available for monitoring. Shorter intervals between population inventories could allow more aggressive harvest policies with the same level of risk, but these inventories are expensive, invasive, and time-consuming. Our information suggests that no matter what harvest level is chosen, stakeholders should understand that estimates and management recommendations are based on uncertain data, and that if the 
population should decline, long-term harvest moratoriums may be required to regain the current number of bears.

\section{ACKNOWLEDGEMENTS}

Financial support for this work was provided by the Greenland Home Rule Government, the Government of the Northwest Territories, the Government of Nunavut, Parks Canada, local Hunters' and Trappers' Organizations, the Nunavut Wildlife Management Board, the Polar Continental Shelf Project, the University of Saskatchewan, and the U.S. National Marine Mammal Laboratory. Hunters of Pond Inlet, Clyde River, Qikiqtarjuak, and Savissivik contributed their local and traditional knowledge of polar bears and participated in the work and harvest program. We particularly thank Sam Palituq, David Kooneeliusie, and Jako Allooloo for their assistance in the field.

\section{REFERENCES}

AMSTRUP, S. 1995. Movements, distribution, and population dynamics of polar bears in the Beaufort Sea. Doctoral dissertation, University of Alaska, Fairbanks.

ARVESON, J.N. 1969. Jackknifing U-statistics. Annals of Mathematics and Statistics 40:2076-2100.

BURNHAM, K.P. 1993. A theory for combined analysis of ring recovery and recapture data. In: Lebreton, J.D., and North, P.M., eds. Marked individuals in the study of bird populations. Basel, Switzerland: Birkhäuser. 199-213.

BURNHAM, K.P., and ANDERSON, D.R. 2002. Model selection and inference: A practical information-theoretic approach. New York: Springer-Verlag.

CALVERT, W., and RAMSAY, M.A. 1998. Evaluation of age determination of polar bears by counts of cementum growth layer groups. Ursus 10:449-453.

CAUGHLEY, G. 1977. Analysis of vertebrate populations. New York: John Wiley \& Sons.

DEROCHER, A.E., and STIRLING, I. 1992. The population dynamics of polar bears in western Hudson Bay. In: McCullough, D.R., and Barret, R.H., eds. Wildlife 2001: Populations. London: Elsevier Applied Science. 1150-1159.

- 1995. Temporal variation in reproduction and body mass of polar bears in western Hudson Bay. Canadian Journal of Zoology 73:657-1665.

FERGUSON, S.H., TAYLOR, M.K., and MESSIER, F. 1997. Space-use of polar bears in and around Auyuittuq National Park, Northwest Territories, during the ice-free period. Canadian Journal of Zoology 75:1585-1594.

FERGUSON, S.H., TAYLOR, M.K., ROSING-ASVID, A., BORN, E.W., and MESSIER, F. 2000. Relationships between denning of polar bears and conditions of sea ice. Journal of Mammalogy $81: 1118-1127$.

FURNELL, D.J., and SCHWEINSBURG, R.E. 1984. Population dynamics of central Arctic polar bears. Journal of Wildlife Management 48:722-728.
JOLLY, G.M. 1965. Explicit estimates from capture-recapture data with both death and immigration stochastic model. Biometrika 52:225-247.

LEBRETON, J.D., BURNHAM, K.P., CLOBERT, J., and ANDERSON, D.R. 1992. Modelling survival and testing biological hypotheses using marked animals: A unified approach with case studies. Ecological Monographs 62:67-118.

MANLY, B.F.J. 1997. Randomization, bootstrap and Monte Carlo methods in biology. London: Chapman \& Hall.

McCULLAGH, P., and NELDER, J.A. 1991. Generalized linear models. London: Chapman \& Hall.

McDONALD, T.L., and AMSTRUP, S.C. 2001. Estimation of population size using open mark-recapture models. Journal of Agricultural, Biological, and Environmental Statistics 6: 206-220.

McLOUGHLIN, P.D., and MESSIER, F. 2004. Relative contributions of sampling error in initial population size and vital rates to outcomes of population viability analysis. Conservation Biology 18:1665-1669.

McLOUGHLIN, P.D., TAYLOR, M.K., CLUFF, H.D., GAU, R.J., MULDERS, R., CASE, R.L., and MESSIER, F. 2003. Population viability of barren-ground grizzly bears in Nunavut and the Northwest Territories. Arctic 56(2):185-190.

PAETKAU, D., AMSTRUP, S.C., BORN, E.W., CALVERT, W., DEROCHER, A.E., GARNER, G.W., MESSIER, F., STIRLING, I., TAYLOR, M.K., WIIG, Ø., and STROBECK, C. 1999. Genetic structure of the world's polar bear populations. Molecular Ecology 8:1571-1584.

PBTC (POLAR BEAR TECHNICAL COMMITTEE). 2001. Minutes of 2001 meeting of the Federal and Provincial Polar Bear Technical Committee, 4-5 February 2001. Available from the Canadian Wildlife Service, 5320 - 122 Street, Edmonton, Alberta T6H 3S5.

POLLOCK, K.H., NICHOLS, J.D., BROWNIE, C., and HINES, J.E. 1990. Statistical inference for capture-recapture experiments. Wildlife Monographs 107. $97 \mathrm{p}$.

RAMSAY, M.A., and STIRLING, I. 1988. Reproductive biology and ecology of female polar bears (Ursus maritimus). Journal of Zoology (London) 214:601-634.

SEBER, G.A.F. 1965. A note on the multiple recapture census. Biometrika 52:249-259.

1982. The estimation of animal abundance and related parameters. New York: Macmillan.

STIRLING, I., CALVERT, W., and ANDRIASHEK, D. 1980. Population ecology studies of the polar bear in the area of southeastern Baffin Island. Edmonton: Canadian Wildlife Service Occasional Paper No. 33.

STIRLING, I., SPENCER, C., and ANDRIASHEK, D. 1989. Immobilization of polar bears (Ursus maritimus) with Telazol in the Canadian Arctic. Journal of Wildlife Diseases 25:159-168.

STIRLING, I., LUNN, N.J., and IACOZZA, J. 1999. Long-term trends in the population ecology of polar bears in western Hudson Bay in relation to climatic change. Arctic 52(3): 294-306.

TAYLOR, M., and LEE, J. 1995. Distribution and abundance of Canadian polar bear populations: A management perspective. Arctic 48(2):147-154. 
TAYLOR, M.K., BUNNELL, F., DeMASTER, D., SCHWEINSBURG, R., and SMITH, J. 1987a. ANURSUS: A population analysis system for polar bears (Ursus maritimus). International Conference on Bear Research and Management 7:117-125.

TAYLOR, M.K., CARLEY, J.S., and BUNNELL, F.L. 1987 b. Correct and incorrect use of recruitment rates for marine mammals. Marine Mammal Science 3:171-178.

TAYLOR, M.K., KUC, M., and ABRAHAM, D. 2000. Vital Rates: Population parameter analysis program for species with threeyear reproductive schedules. Iqaluit: Government of Nunavut.

TAYLOR, M.K., AKEEAGOK, S., ANDRIASHEK, D., BARBOUR, W., BORN, E.W., CALVERT, W., FERGUSON, S., LAAKE, J., ROSING-ASVID, A., STIRLING, I., and MESSIER, F. 2001a. Delineating Canadian and Greenland polar bear (Ursus maritimus) populations by cluster analysis of movements. Canadian Journal of Zoology 79:690-709.
TAYLOR, M.K., OBBARD, M., POND, B., KUC, M., and ABRAHAM, D. 2001b. RISKMAN: Stochastic and deterministic population modeling RISK MANagement decision tool for harvested and unharvested populations. Iqaluit: Government of Nunavut.

TAYLOR, M.K., LAAKE, J., CLUFF, H.D., RAMSAY, M., and MESSIER, F. 2002. Managing the risk from hunting for the Viscount-Melville Sound polar bear population. Ursus 13: $185-202$.

WHITE, G.C. 2000. Population viability analysis: Data requirements and essential analyses. In: Boitani, L., and Fullers, T.K., eds. Research techniques in animal ecology: Controversies and consequences. New York: Cambridge University Press. $288-331$.

WHITE, G.C., BURNHAM, K.P., and ANDERSON, D.R. 2000. Advanced features of program MARK. Fort Collins: Colorado State University. 